\title{
Damping for Wind Turbine Electrically Excited Synchronous Generators
}

\author{
Wang Tianyu ${ }^{\dagger}$, Li Guojie*, Zhang Yu** and Fang Chen**
}

\begin{abstract}
The electrically excited synchronous generator (EESG) is applied in wind turbine systems recently. In an EESG control system, electrical torque is affected by stator flux and rotor current. So the control system is more complicated than that of the permanent-magnet synchronous generator (PMSG). Thus, the higher demanding of the control system is required especially in case of wind turbine mechanical resonance. In this paper, the mechanism of rotor speed resonant phenomenon is introduced from the viewpoint of mechanics firstly, and the characteristics of an effective damping torque are illustrated through system eigenvalues analysis. Considering the variables are tightly coupled, the four-order small signal equation for torque is derived considering stator and rotor control systems with regulators, and the bode plot of the closed loop transfer function is analyzed. According to the four-order mathematical equation, the stator flux, stator current, and electrical torque responses are derived by torque reference step and ramp in MATLAB from a pure mathematical deduction, which is identical with the responses in PSCAD/EMTDC simulation results. At last, the simulation studies are carried out in PSCAD software package to verify the resonant damping control strategy used in the EESG wind turbine system.
\end{abstract}

Keywords: Electrically excited synchronous generator, Stator flux oriented, Small signal analysis, Damping torque control

\section{Introduction}

2015 is a great year for wind power industry, with $44 \%$ annual market growth. More than $51 \mathrm{GW}$ of new wind power capacity was brought on line in 2014, a sharp rise in comparison to 2013, when global installations were just over $35.6 \mathrm{GW}$. The previous record was set in 2012 when over $45 \mathrm{GW}$ of new capacity was installed globally $[1,2]$.

The variable-speed wind turbine is the most popular turbine type in the market for its good performance on wind energy capturing [3]. There are two major types of variable-speed wind turbines, the doubly-fed induction generator (DFIG) and the synchronous wind turbine. Both of them can realize the decoupling control between active power and reactive power. The most advantage of the DFIG is the low cost of the electrical converter for the rotor converter which only deals with approximately $30 \%$ of the total power. At the end of 2010, this topology has a fraction of the wind-energy market, which is close to $50 \%$ [4]. But the disadvantages of the DFIG attract more and more attention recently, for instance, the DFIG is easily influenced by grid faults for the stator windings are directly connected to the grid. Another drawback is the high maintenance cost of the gearbox, which has the longest

$\dagger$ Corresponding Author: Dept. of Electrical Engineering, Shanghai Jiao Tong University, Shanghai China. (wty_wty3000@163.com)

* Dept. of Electrical Engineering, Shanghai Jiao Tong University. (liguojie@sjtu.edu.cn)

** Electric Power Research Institute, State Grid Shanghai Municipal Electric Power Company, Shanghai, China (P3chang@qq.com, fangc02@gmail.com )

Received: March 11, 2015; Accepted: December 15, 2015 downtime compared to the other components and is found to be the most critical component causing failures in wind turbine generator systems [5].

The synchronous wind turbine system provides full decoupling between the generator and the grid by a fullpower back-to-back converter, which results in higher power capture at different wind speeds and enhanced capability to fulfill the low voltage ride through requirement. There are two kinds of synchronous generators: permanentmagnet synchronous generator (PMSG) and electrically excited synchronous generator (EESG), and the former has a comparatively large share of the market. The EESG is interesting since the price of rare-earth rises which is the core material of the PMSG [6]. The rotor excitation of the EESG can be flexibly regulated and the terminal voltage can be adjusted to a reasonable range. So this kind of synchronous generators attracts wind turbine manufactures, and many multi-MW EESGs are available in the market [7].

From the view of mechanics, the wind turbine system consists of three parts: turbine rotor, shaft and generator. Thus, it can be treated as a multi-mass mechanical system. Mechanical torque produced by wind acts on the turbine rotor then it is delivered to the generator though the shaft system. During the ideal state, the input mechanical torque is balanced by the opposing electromagnetic torque, and the three parts rotate with the same angular speed. However, for a multi-mass mechanical system, the problem of mechanical resonance is inherent and discussed by many researchers. Salman [8] proposed that the multi-mass model had a more convincing simulation result than the lumped model. Oversimplification of the modeling of the 
windmill mechanical drive train could introduce significant error in the value of critical clearing time that defines the stability limit of an integrated wind farm. Mandic [9] pointed that both the direct drive wind turbine and the gearbox-based drive train wind turbine had the problem of torsional deformations caused by the flexible mechanical coupling between the generator shaft and the turbine rotor. Refs [10] and [11] analyzed the effective shaft stiffness of the direct drive wind turbine. Although the stiffness of the shaft in the direct drive wind turbine is relative high compared to that in the gear-box based wind turbine with a longer shaft. The phenomenon of mechanical resonance is still significant: a small mechanical angle deviation in the rotor leads to a large electrical angle deviation in the generator, the shaft shows a "softer" characteristic.

The methods of preventing mechanical resonance have also been published in many papers. In [10], a popular way was mentioned that the damping rubber was mounted on the drive train shaft. The disadvantage of this way is costly and requires additional installation space on the drive train shaft. In [12], the rotation speed feedback algorithm is introduced to reduce the speed variation of the generator. Akhmatov [13] indicated that the pitch control method was not suitable to prevent mechanical resonance because its bandwidth was much lower, and the effective method was to utilize the electromagnetic torque. Hua Geng [14] compared the mechanical damping performances of three power control strategies for the PMSG. Unlike power smoothing control and constant power control, the maximal power point tracking control using the power signal feedback algorithm [15] implemented in the generator side has inherent abilities on the oscillation damping. Summarizing the above methods, there is one common idea to suppress the resonance that is to add an active damping torque which magnitude is proportional to the resonant signal. And the resonant signal is picked up from the rotation speed by a band-pass filter. However, the objects studied above are all PMSGs, the research based on the EESG is rare mentioned in published. The electromagnetic torque which is generated by the interaction between the flux linkages produced by rotor and threephase stator currents is the key point to solve the problem. In the PMSG control system, torque control is well satisfied by regulating the stator current without considering the rotor flux because the magnetic field intensity of the rotor permanent magnet is constant. Unlike PMSGs, there are two variables affecting the torque control of EESGs, one of which is varied associated with the rotor current. The control system of EESGs is more complex than that of PMSGs, in plain terms, the variables associated with the torque are mutual coupled, the mechanism of the whole torque control system is difficult to be analyzed. Considering that the variables are tightly coupled, the small signal method $[16,17]$ is used to analyze the characteristics of the electrical torque for verifying the damping torque strategy applied to EESGs in this paper.
In section 2, wind turbine shafting system resonance is analyzed based on a two-mass model. In section 3, the model of the EESG under the MT coordinates has been deduced from the one of the EESG in the basic $d q$-rotation frame. In section 4 , The four-order small signal equation of torque is derived considering stator and rotor control parameters, and the closed loop transfer function characteristics of torque are analyzed. In Section 5, the simulation studies of the EESG wind turbine are carried out in PSCAD software package to verify the system model and the effectiveness of resonance damping control strategy.

\section{Mechanical Model of Wind Turbine and Damping Torque Analysis}

\subsection{The model of wind turbine drive train}

As mentioned in the introduction, the wind turbine can be equivalent to a multi-mass mechanical system, a twomass model is adopted to reflect the mechanical characteristics of the EESG, for its rotor and generator are directly connected by a short shaft. The equations for the two-mass model is shown below:

$$
\left\{\begin{array}{l}
\dot{\omega}_{h}=\frac{1}{J_{h}}\left(T_{m}-K \theta\right) \\
\dot{\omega}_{r}=\frac{1}{J_{g}}\left(K \theta-T_{e}\right) \\
\dot{\theta}=\omega_{h}-\omega_{r}
\end{array}\right.
$$

Where $\omega_{h}$, and $\omega_{r}$ are the rotational speed of the wind turbine and generator, respectively; $J_{h}$ and $J_{g}$ are the turbine and generator intertie, respectively; $T_{m}$ and $T_{e}$ are the turbine mechanical torque and generator electromagnetic torque, respectively; $\mathrm{K}$ is the shaft stiffness; $\theta$ is the electrical angle of the shaft, assuming the rotor with one pair of poles.

The mechanical resonant frequency with the range from $0.1 \mathrm{~Hz}$ to $10 \mathrm{~Hz}[18]$ is expressed as

$$
\omega_{r e}=\sqrt{K \frac{J_{h}+J_{g}}{J_{h} J_{g}}}
$$

where $\omega_{r e}$, is the mechanical resonant frequency.

\subsection{Mechanism of damping torque}

In order to have a deep insight in mechanism of mechanical resonance, the small signal analysis is used in this section. For a simplified analysis, the wind speed is supposed to be constant, the mechanical torque acted on the wind turbine rotor is unchanged and neglecting the 


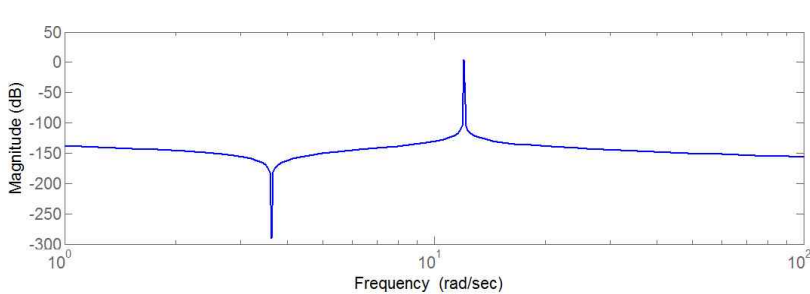

Fig. 1. Magnitude plot of the wind turbine mechanical system

effect of blade pitch control. Rewrite Eq. (1) into small signal increment equations:

$$
\left[\begin{array}{l}
\Delta \dot{\omega}_{h} \\
\Delta \dot{\omega}_{r} \\
\Delta \dot{\theta}
\end{array}\right]=\left[\begin{array}{ccc}
0 & 0 & -\frac{K}{J_{h}} \\
0 & 0 & \frac{K}{J_{g}} \\
1 & -1 & 0
\end{array}\right]\left[\begin{array}{l}
\Delta \omega_{h} \\
\Delta \omega_{r} \\
\Delta \theta
\end{array}\right]+\left[\begin{array}{l}
0 \\
\frac{1}{J_{g}} \\
0
\end{array}\right] \Delta T_{e}
$$

where $\Delta \omega_{h}$ and $\Delta \omega_{r}$ are wind turbine rotational speed increment and generator rotational speed increment, respectively. $\Delta \theta$ is the electrical angle increment of the shaft; $\Delta T_{e}$ is the electromagnetic torque increment.

From Eq. (3), the magnitude plot of $\Delta \omega_{r} / \Delta T_{e}$ is depicted in Fig. 1. The mechanical parameters are given in appendix. There is a large peak at the point with the angular frequency of $12.56 \mathrm{rad} / \mathrm{s}$ in Fig. 1. This means that the rotation speed of the rotor has a very high gain response to the electromagnetic torque at that frequency point, and the generator speed is expected to oscillate at $12.56 \mathrm{rad} / \mathrm{s}$ when the electromagnetic torque changes.

Adding an electromagnetic torque to the generator is proposed to damp the above large peak. The particular active damping torque can be got by a band-pass filter with the same band-pass frequency as the mechanical resonant frequency:

$$
T_{p}(s)=G_{\text {band }- \text { pass }}(s) \omega_{r}(s)
$$

where $T_{P}$ is damping torque; $G_{\text {band-pass }}$ is band-pass filter with the transfer function:

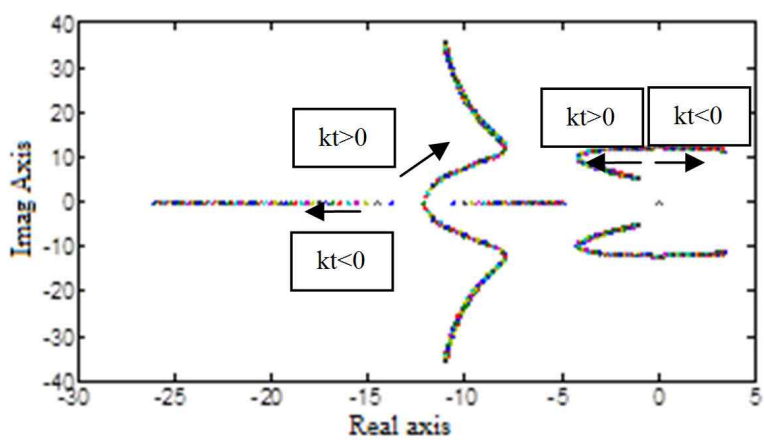

Fig. 2. System eigenvalues curves versus $k_{t}$

$$
G_{\text {band-pass }}(s)=k_{t} \frac{\frac{s}{\omega_{r e}}}{1+2 z \frac{s}{\omega_{r e}}+\frac{s^{2}}{\omega_{r e}{ }^{2}}}
$$

The small signal equation of the system with a damping torque added is deduced as

$$
\left[\begin{array}{l}
\Delta \dot{\omega}_{h} \\
\Delta \dot{\omega}_{r} \\
\Delta \dot{\theta} \\
\Delta \dot{\mathrm{y}}_{1} \\
\Delta \dot{y}_{2}
\end{array}\right]=\left[\begin{array}{ccccc}
0 & 0 & -\frac{K}{J_{h}} & 0 & 0 \\
0 & 0 & \frac{K}{J_{g}} & -\frac{k_{t} \omega_{r e}}{J_{g}} & 0 \\
1 & -1 & 0 & 0 & 0 \\
0 & 1 & 0 & -2 \omega_{r e} z & -\omega_{r e}^{2} \\
0 & 0 & 0 & 1 & 0
\end{array}\right]\left[\begin{array}{l}
\Delta \omega_{h} \\
\Delta \omega_{r} \\
\Delta \theta \\
\Delta \mathrm{y}_{1} \\
\Delta y_{2}
\end{array}\right]+\left[\begin{array}{l}
0 \\
-\frac{1}{J_{g}} \\
0 \\
0 \\
0
\end{array}\right] \Delta T_{e}
$$

where $\Delta y_{1}$ and $\Delta y_{2}$ are intermediate variables.

From Eq. (5), $\mathrm{k}_{\mathrm{t}}$ is a single variable and $\mathrm{K}, \mathrm{J}_{\mathrm{h}}, \mathrm{J}_{\mathrm{g}}, \omega_{\mathrm{re}}, \mathrm{z}$ are constant parameters, the system eigenvalue locus is shown in Fig. 2.

From Fig. 2, when $\mathrm{k}_{\mathrm{t}}$ is zero (no damping torque added), there is a pair of eigenvalue roots located on the imaginary axis, and the system is in an unstable state. When $\mathrm{k}_{\mathrm{t}}$ increases above zero (normal damping torque added), the roots trajectory moves toward left, the system is stable. However, if $\mathrm{k}_{\mathrm{t}}$ continually increases, the roots trajectory moves to the imaginary axis again and another pair of eigenvalue roots move to up and down respectively. This means the system has an insufficient damping. When $\mathrm{k}_{\mathrm{t}}$ decreases under zero (the torque has a 180 degree shift compared to normal damping torque), the roots located at the right half of the complex plane, the system is unstable. So the system can be well damped if the electrical torque traces the damping torque reference with a little phase shift

\section{Modeling of Electrically Excited Synchronous Generator}

An EESG wind turbine system as shown in Fig. 3 consists of five main parts: wind turbine, EESG, back-toback converter, rotor excitation, and transformer.

Although in $d q$-rotation frame [19], the basic torque control is straightforward, the advanced control strategies, such as keeping the terminal voltage of the stator constant

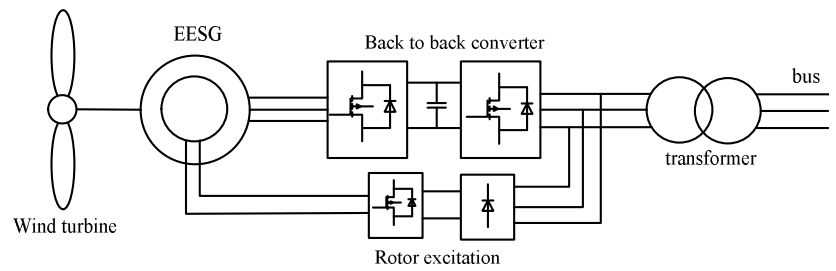

Fig. 3. EESG wind turbine system 


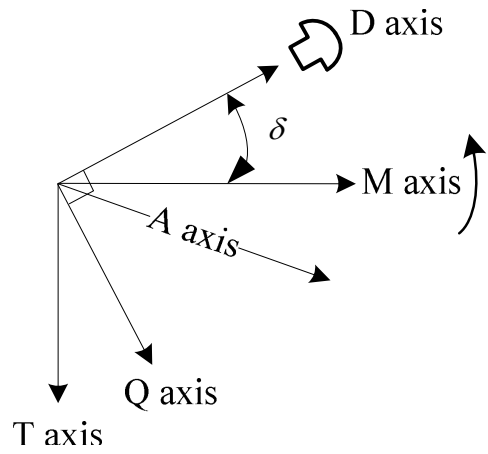

Fig. 4. Relationship between $\mathrm{MT}$ axis and $d q$ axis

and unity power factor operation, are implemented complexly. These requirements are very important for the parameters of a full-power converter can be optimally designed. So another model of the EESG based on the stator flux orientation is an alyzed as follows.

In the stator flux oriented frame, we have the following definitions: the rotation speed of the frame is the same as that of the stator flux, the $M$ axis is coincided with the stator flux, the $\mathrm{T}$ axis lags the $\mathrm{M}$ axis 90 degree as shown in Fig. 4, so the stator flux has zero component in the $\mathrm{T}$ axis.

As defined above, the difference angle between the $\mathrm{M}$ axis and $\mathrm{d}$ axis is the torque angle, the rotation speed of the $\mathrm{M}$ axis is expressed as

$$
\omega_{s m}=\omega_{r}-\frac{d \delta}{d t}
$$

Other variables can be transformed by the following matrix which is deduced through the geometric relationship of two rotation frames.

$$
\left[\begin{array}{c}
f_{s m} \\
f_{s t}
\end{array}\right]=\left[\begin{array}{cc}
\cos \delta & \sin \delta \\
-\sin \delta & \cos \delta
\end{array}\right]\left[\begin{array}{l}
f_{d s} \\
f_{q s}
\end{array}\right]
$$

where $f_{d s}$ and $f_{q s}$ are the components at the $d q$ axis. $f_{s m}$ and $f_{s t}$ are the components at the MT axis.

For a simple analysis, the flux equation of the cylindrical rotor EESG based on the stator flux oriented frame is deduced assuming $L_{d}=L_{q}$ :

$$
\left[\begin{array}{l}
\psi_{s m} \\
\psi_{s t} \\
\psi_{f}
\end{array}\right]=\left[\begin{array}{ccc}
L_{d} & 0 & \cos \delta L_{m d} \\
0 & L_{q} & -\sin \delta L_{m d} \\
\frac{3}{2} \cos \delta L_{m d} & -\frac{3}{2} \sin \delta L_{m d} & L_{f}
\end{array}\right]\left[\begin{array}{l}
i_{s m} \\
i_{s t} \\
i_{f}
\end{array}\right]
$$

Considering that the $\mathrm{M}$ axis is coincide with stator flux, the electrical torque can be expressed as

$$
T_{e}=i_{s t} \psi_{s m}
$$

From (9), the electrical torque only depends on the stator current $i_{\text {st }}$ when $\psi_{s m}$ is kept constant. However, reviewing (8), when the stator current $i_{s t}$ has a little increment and the rotor current $i_{f}$ has no change, the torque angular increase for $\psi_{s t}$ must be zero in the stator flux oriented frame, then the rotor excitation current is increased in order to keep the magnitude of the stator flux unchanged. In the above process, the stator current $i_{s t}$ and rotor current $i_{f}$ interact with each other, so the process of torque control needs a further analysis which is described in next section.

Through (6) and (9), EESG's voltage equations under the stator flux oriented coordination are obtained as the function of $i_{s m}, i_{s t}$ and $i_{f}$ :

$$
\left\{\begin{array}{l}
v_{s m}=r_{s} i_{s m}+L_{d} \frac{d i_{s m}}{d t}+\frac{d \cos \delta L_{m d} i_{f}}{d t} \\
v_{s t}=r_{s} i_{s t}-\omega_{s m} \psi_{s m} \\
e_{f}=r_{f} i_{f}+L_{f} \frac{d i_{f}}{d t}+\frac{3}{2} L_{m d} \frac{d \cos \delta i_{s m}}{d t}-\frac{3}{2} L_{m d} \frac{d \sin \delta i_{s t}}{d t}
\end{array}\right.
$$

\section{Modeling of Torque Control System of Electrically Excited Synchronous Generator}

The main advantage of the stator flux oriented coordination is to achieve unity power factor easily [20, 21]. From the relationship between the stator voltage and stator flux, keeping the stator flux constant can make the stator voltage unchanged which is aligned to the $\mathrm{T}$ axis (when the rotor speed changes, the magnitude of the stator flux is inverse to the $r$ otor speed). The magnitude of the stator flux is settled by regulating the rotor current $i_{f}$, and the stator current $i_{s m}$ is set to zero in the steady state. The reference of $i_{s t}$ is got though the torque reference dividing $\psi_{s m}$, then the electrical torque can be settled by regulating the stator current $i_{s t}$. The stator current only has component

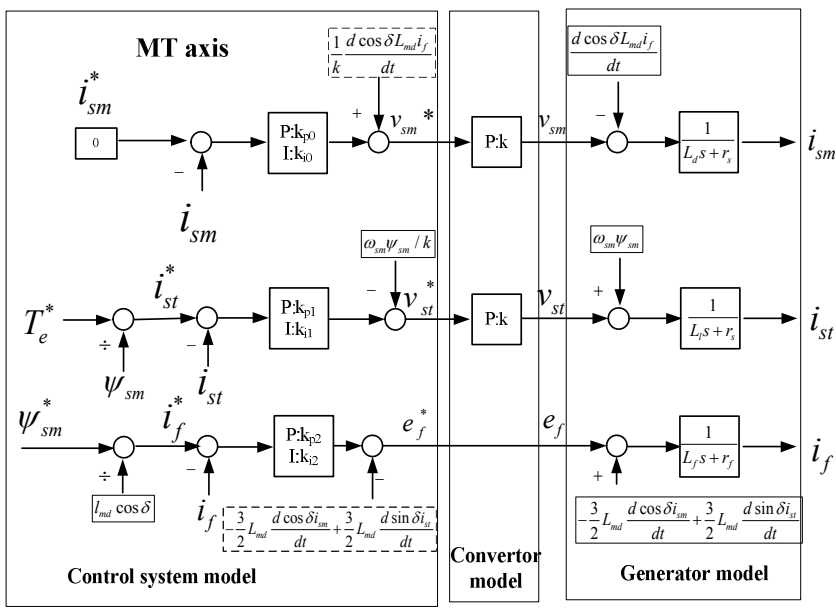

Fig. 5. Control scheme of EESG 
at the $T$ axis which is in phase with the stator voltage. Then power factor is the unity. The basic PI regulators are used in the whole control system, and the control diagram is shown in Fig. 5.

The whole control system Eq. (11) is derived from Fig. 5. Assuming the differential item in the generator model is well compensated by that in the control system model from Fig. 5, the system state-variable Eq. (12) is obtained to study the performance of the whole system.

From (12) and Fig. 5, the stator current $i_{s m}$ and state variable $x_{0}$ have no deal with the torque and stator flux control, so the above variables can be omitted in the analysis of the torque characteristics. Considering the rest four variables of state vector elements are tightly coupling, the small signal model is used to analyze the characteristics of the EESG torque.

Assuming that those variables have a little increment at the operation point without considering rotor speed change, the small signal matrix of the control system is deduced:

$$
\left\{\begin{array}{l}
\dot{x}_{0}=-i_{s m} \\
v_{s m}=k k_{p 0}\left(-i_{s m}\right)+k k_{i 0} x_{1}+\frac{d \cos \delta L_{m d} i_{f}}{d t} \\
\dot{x}_{1}=\frac{T_{e}^{*}}{\psi_{s m}}-i_{s t} \\
v_{s t}=k k_{p 1}\left(\frac{T_{e}^{*}}{\psi_{s m}}-i_{s t}\right)+k_{i 1} x_{1} \\
\dot{i}_{s t}=\frac{v_{s t}}{L_{l}}-\frac{r_{s}}{L_{l}} i_{s t} \\
\dot{x}_{2}=\frac{\psi_{s m}^{*}}{\cos \delta L_{m d}}-i_{f} \\
e_{f}=k_{p 2}\left(\frac{\psi_{s m}^{*}}{\cos \delta L_{m d}}-i_{f}\right)+k_{i 2} x_{5}+\frac{3}{2} L_{m d} \frac{d \cos \delta i_{s m}}{d t} \\
-\frac{3}{2} L_{m d} \frac{d \sin \delta i_{s t}}{d t} \\
\dot{i}_{f}=\frac{e_{f}}{L_{f}}-\frac{r_{f}}{L_{f}} i_{f}
\end{array}\right.
$$

where $x_{1}, x_{2}, x_{3}$ are the intermediate variables, $k_{p 0}, k_{p 1}, k_{p 2}$, $k_{i 0}, k_{i 1}, k_{i 2}$ are PI controller parameters; $k$ is the equivalent voltage amplification of the stator converter.

$$
\left\{\begin{array}{l}
X=\left[\begin{array}{llllll}
x_{0} & x_{1} & x_{2} & i_{s m} & i_{s t} & i_{f}
\end{array}\right]^{T} \\
U=\left[\begin{array}{ll}
T_{e}^{*} & \psi_{s m}^{*}
\end{array}\right]^{T} \\
\dot{X}=A X+B U
\end{array}\right.
$$

where $\mathrm{X}$ is the state vector, $\mathrm{U}$ is the vector of input signals.

$$
\left\{\begin{array}{l}
\Delta X=\left[\begin{array}{llll}
\Delta x_{1} & \Delta i_{s t} & \Delta x_{2} & \Delta i_{f}
\end{array}\right]^{T} \\
\Delta U=\left[\begin{array}{lll}
\Delta T_{e}^{*} & \Delta \psi_{s m}^{*}
\end{array}\right]^{T} \\
\Delta A=\left[\begin{array}{cccc}
0 & F_{2} & 0 & -F_{3} \\
G_{4} & G_{2} & 0 & -G_{3} \\
0 & H_{3} & 0 & -H_{2} \\
0 & I_{3} & I_{4} & -I_{2}
\end{array}\right] \\
\Delta B=\left[\begin{array}{cccc}
0 & 0 & H_{1} & I_{1} \\
F_{1} & G_{1} & 0 & 0
\end{array}\right]^{T} \\
\Delta \dot{X}=\Delta A \Delta X+\Delta B \Delta U
\end{array}\right.
$$

where $A_{i j}, B_{i j}$ are matrix elements shown in appendix.

From (9) and (13), a torque related four-order small signal output matrix is obtained as

$$
\left\{\begin{array}{l}
\Delta Y=\left[\Delta T_{\mathrm{e}}\right] \\
\Delta U=\left[\begin{array}{lll}
\Delta T_{e}^{*} & \Delta \psi_{s m}^{*}
\end{array}\right]^{T} \\
\Delta C=\left[\begin{array}{llll}
0 & J_{1} & 0 & J_{2}
\end{array}\right] \\
\Delta D=\left[\begin{array}{lll}
0
\end{array}\right] \\
\Delta Y=\Delta C \Delta X+\Delta D \Delta U
\end{array}\right.
$$

Where $J_{1}, J_{2}$ are matrix elements as shown in appendix.

According to (13) and (14), the bode plot of the closed loop torque transfer function is derived as shown in Fig. 6.

There are four groups of curves for different PI parameters of the torque control and flux control regulators as shown in Fig. 6. All curves have the similar characteristics at the range from $0.1 \mathrm{~Hz}$ to $10 \mathrm{~Hz}$ that $\mathrm{p}$ hase lagging and magnitude gain are almost zero. However, from the frequency range above $20 \mathrm{~Hz}$, the magnitude gain decreases and phase lagging increases, the performance of tracing torque reference is obviously worse. Considering the mechanical resonant frequency of the direct driven synchronous wind turbine is general at range from $0.1 \mathrm{~Hz}$ to $10 \mathrm{~Hz}$ [20], at that frequency range the electrical torque can trace the torque

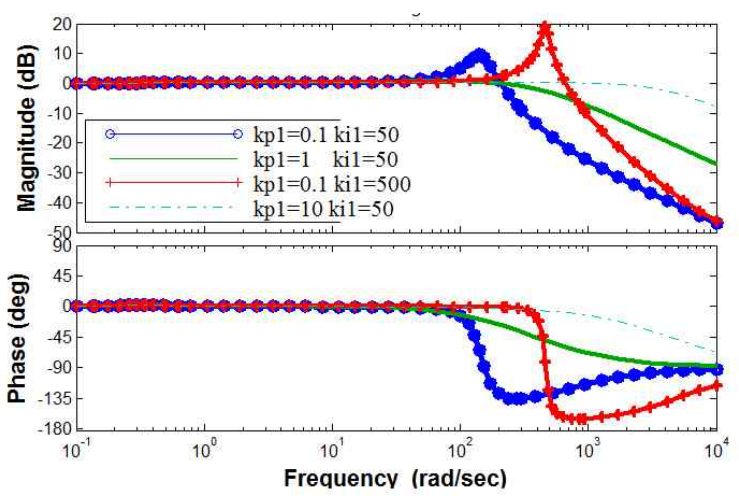

Fig. 6. Bode plot of the closed loop torque transfer function 
reference precisely, so the damping torque control strategy can be implemented in this system well.

\section{Model Verified and Resonant Damping Simulation}

\subsection{Model verified}

The mathematical model of the EESG control system is established in section 4, and the model is verified in this section.

Firstly, the four-order small signal model is established in MATLAB according to equations (12) and (14). The rotation speed of the rotor is assumed to be constant in the small signal model for the inertia of wind turbine is very large, so the magnitude of the stator flux reference is unchanged. The variables of the control system such as the torque angle $\delta$, stator current $i_{s t}$, electrical torque $\mathrm{t}_{\mathrm{e}}$ responses to torque reference step and ramp are obtained from pure mathematical derivation in MATLAB. $i_{s t}$ and $t_{e}$ are system state variable and output variable respectively, and $\delta$ can be obtained through

$$
\Delta \delta=\frac{L_{d}}{\cos \delta L_{m d} i_{f}} \Delta i_{s t}-\frac{i_{s t} L_{d}}{\cos \delta L_{m d} i_{f}^{2}} \Delta i_{f}
$$

In step response case, the small increment of the torque reference is stepped to $10 \mathrm{Nm}$ from $0 \mathrm{Nm}$ at $0.05 \mathrm{~s}$; In ramp response case, the small increment is ramped to $10 \mathrm{Nm}$ gradually. The variable responses are shown in Fig. 7 and Fig. 8, respectively.

From Fig. 7, three variables have a little overshoot with the same changing trend. In Fig. 8, the variables increase to the steady state gradually because the excitation of torque reference changes slowly.

Secondly, the comparative simulations are carried out through PSCAD / EMTDC simula tion package. The torque reference steps from $0.8 \mathrm{pu}$ to $0.83 \mathrm{pu}$ in step response case and ramps to $0.83 \mathrm{pu}$ in ramp response case. The simulation results are shown in Fig. 9 and Fig. 10.

Compared with the curves of Fig. 7 and Fig. 8, the corresponding features are almost same omitting the ripple

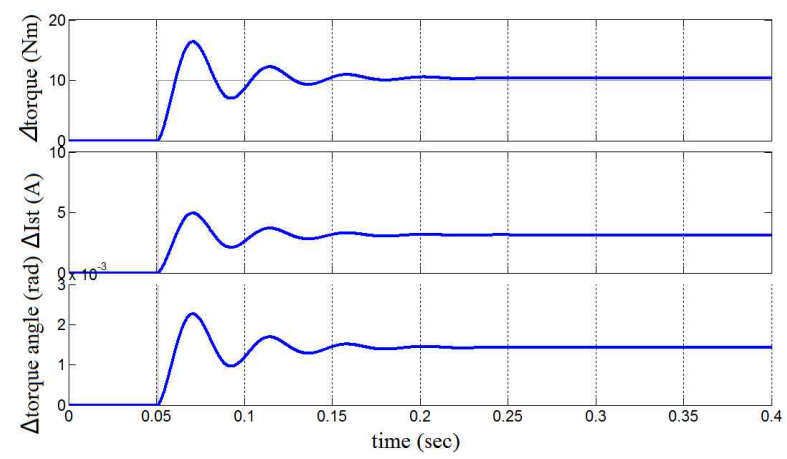

Fig. 7. Dynamic responses of torque reference step case waves in Fig. 9 and Fig. 10. So the small signal model can be proved validly.

\subsection{Resonant damping strategy simulation}

In this section, the resonant damping control strategy implemented in the EESG is verified through PSCAD/ EMTDC package. As known that the basic control

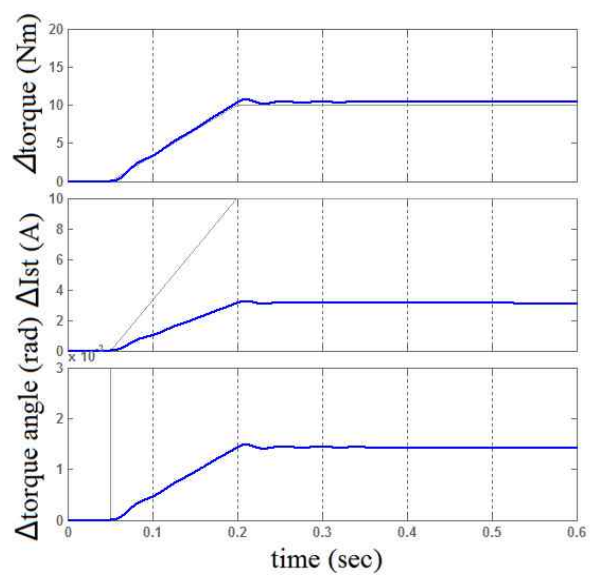

Fig. 8. Dynamic responses of torque reference ramp case

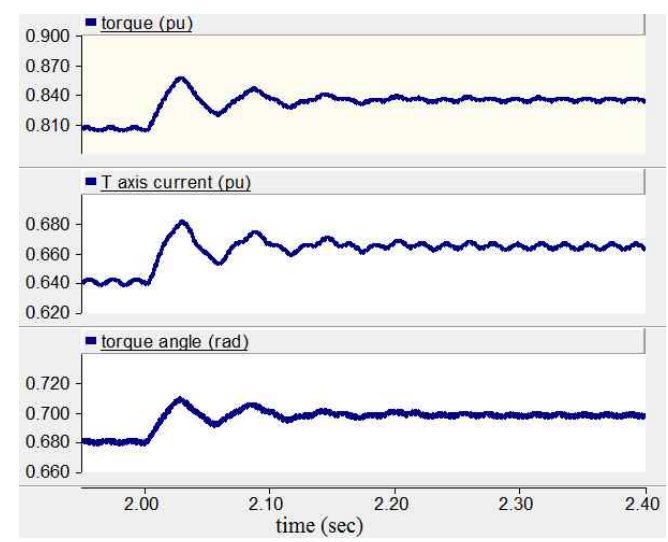

Fig. 9. Dynamic responses of torque reference step case (simulation in PSCAD)

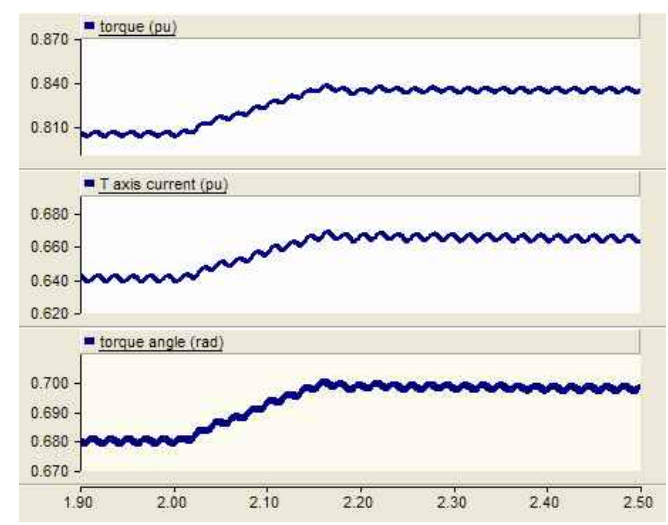

Fig. 10. Dynamic responses of torque reference ramp case (simulation in PSCAD) 

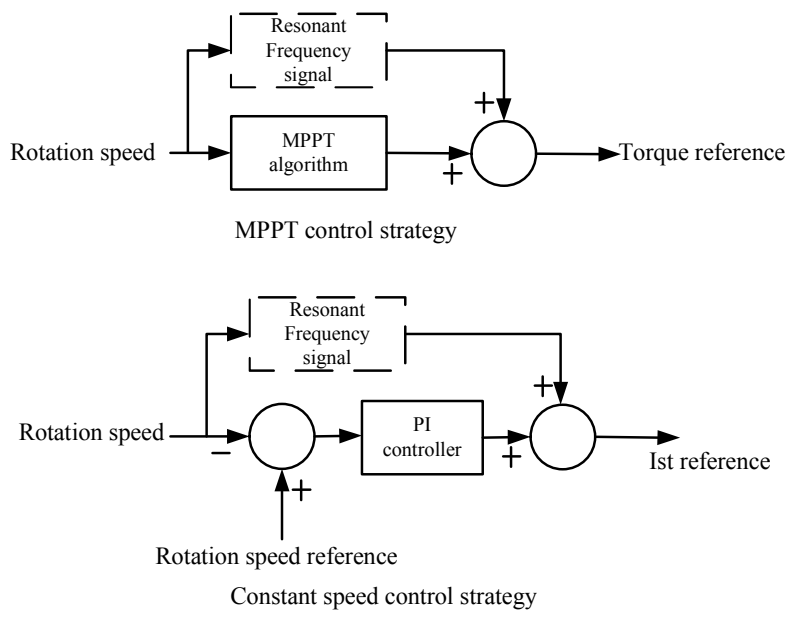

Fig. 11. Scheme of resonant damping control

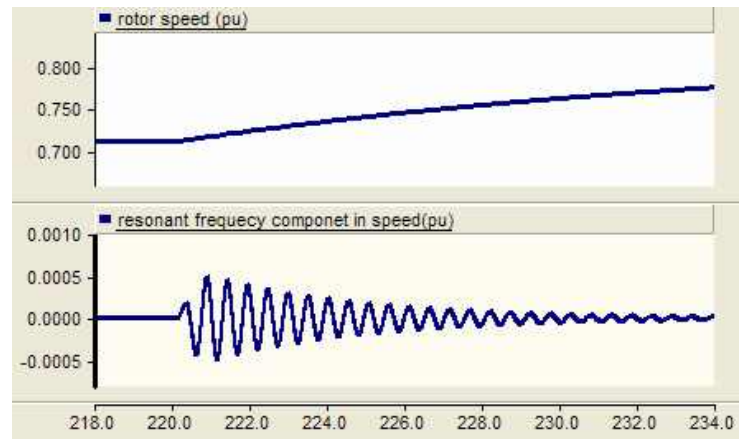

Fig. 12. Rotor speed response without resonant damping control (MPPT control)

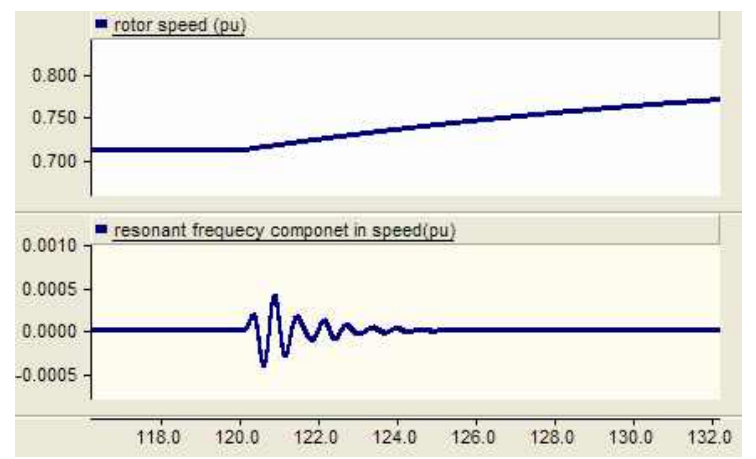

Fig. 13. Rotor speed response with resonant damping control (MPPT control)

algorithms of variable speed wind turbine depends on wind speed. Two typical strategies are maximum power tracking (MPPT) control and constant speed control. In order to achieve MPPT control strategy, the torque reference is applied to the generator which is proportional to the square of the rotation speed. The two algorithms are shown in Fig. 11, and the resonant damping reference is indicted in dotted frame.

In the simulation studies, the wind speed is stepped from $7 \mathrm{~m} / \mathrm{s}$ to $8 \mathrm{~m} / \mathrm{s}$ for MPPT control region and from $13 \mathrm{~m} / \mathrm{s}$ to

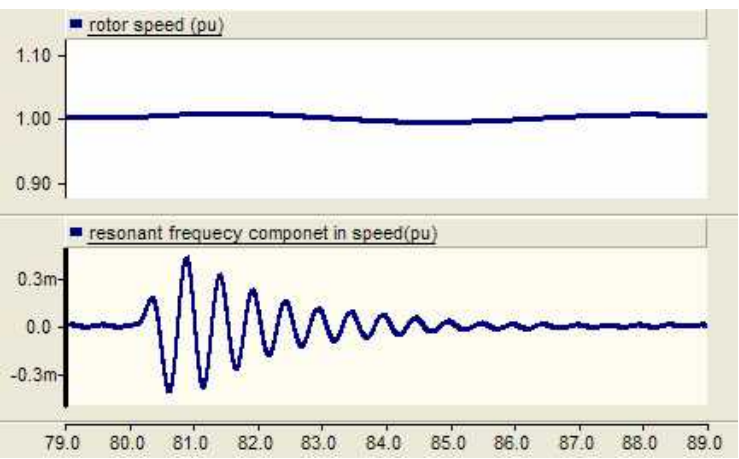

Fig. 14. Rotor speed response without resonant damping control (constant speed control)

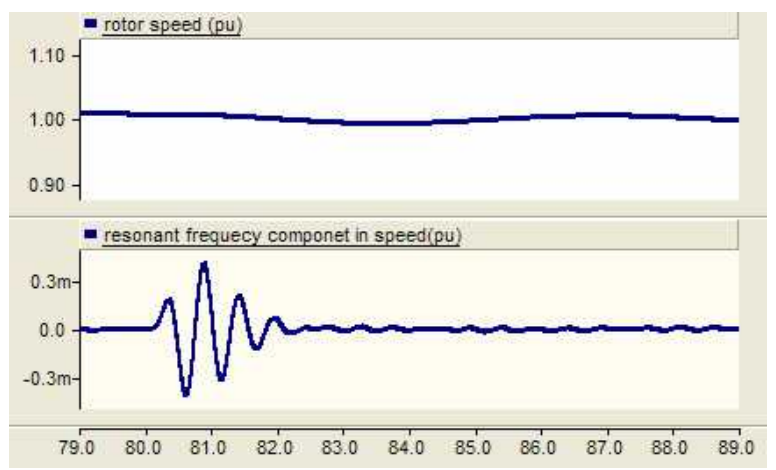

Fig. 15. Rotor speed response with resonant damping control (constant speed control)

$14 \mathrm{~m} / \mathrm{s}$ for constant speed control region. The simulation results are shown below.

As shown in Fig. 12, the resonant component which appears at the same time with wind speed stepped has a slow attenuation trend, because the torque reference of the EESG is proportional to the square of the rotation speed when the EESG works in MPPT strategy. However, the coefficient of proportionality is quite small and the resonant component can't be damped quickly.

As shown in Fig. 14, the resonant component also has a slow attenuation trend for the rotation speed is regulated by the PI controller in the constant speed control method. The attenuation rate depends on the gain of the PI controller at the resonant frequency.

Compared with the above curves, the resonant component decays rapidly when the resonant damping control is applied to the wind turbine. The simulation results indicate that resonant damping control strategy is effective for the EESG wind turbine control system.

\section{Conclusion}

In this paper, wind turbine shafting system resonance in the EESG control system is analyzed, and the damping torque strategy is also proposed based on the two-mass 
model. In order to analyze the characteristics of the strong coupled control system, the four-order small signal equation related to torque and stator flux control is derived. Compared with different control parameters of rotor and stator regulators, the torque reference is tracked well at the frequency below $10 \mathrm{~Hz}$ from the torque closed loop Bode plot.

The four-order small signal model is proved validly by comparing variable responses to the torque reference step from MATLAB pure mathematical deduction and PSCAD package simulation. Then the damping torque strategy is applied to the EESG control system in PSCAD software package, and the simulation results indicate that resonant damping control strategy is effective for the EESG wind turbine control system to decay the resonant component of rotation speed rapidly.

\section{Nomenclature}

$\psi_{q s} \psi_{d s} \quad$ Stator flux fixed to rotor axis

$\psi_{S M} \psi_{S T}$ Stator flux fixed to stator flux axis

$\psi_{f} \quad$ Rotor flux

$L_{d}, L_{q} \quad \mathrm{~d}$ and $\mathrm{q}$ axes inductances

$L_{m d} \quad$ Mutual inductance

$\delta \quad$ Torque angle

$\omega_{r} \quad$ Rotor rotation angular speed

$\omega_{s m} \quad$ Stator flux rotation angular speed

$i_{s t}, i_{s m} \quad$ Stator current fixed to MT axis

$i_{q s}, i_{d s} \quad$ Stator current fixed to $d q$ axis

$i_{f} \quad$ Rotor current

$v_{s t}, \mathrm{v}_{s m} \quad$ Stator voltage fixed to MT axis

$v_{q s}, v_{d s} \quad$ Stator voltage fixed to $d q$ axis

$e_{f} \quad$ Rotor excitation voltage

$T_{e} \quad$ Electrical torque

\section{Acknowledgements}

This work was supported by International S\&T Cooperation Program of China (2013DFG71630), National Natural Science Foundation of China (51477098, 51307107), Specialized Research Fund for the Doctoral Program of Higher Education (20130073120034), and National science and technology support plan (2013 BAA01B04).

\section{References}

[1] “Global wind report annual market update 2014,"[on line]. Available on http://www.gwec.net/publications/

[2] "global wind energy outlook 2014," [on line]. Available on http://www.gwec.net/publications/globalwind-energy-outlook/

[3] Abdullah, "A Pitch control design for optimum energy capture in variable-speed wind turbines," Systems, Signals \& Devices, 2013 10th international multi-conference, Hammamet, Tunisia, Mar. 2013.

[4] M. Liserre, R. Cardenas, M. Molinas, J. Rodriguez, "Overview of multi-MW wind turbines and wind parks," IEEE Trans. on Industrial Electronics, vol. 54, no. 4, pp. 1081-1095, 2011.

[5] Ribrant, J. Stockholm, "Survey of Failures in Wind Power Systems With Focus on Swedish Wind Power Plants During 1997-2005," IEEE Trans. on Energy conversion, vol. 21, no. 1, pp. 167-173, Mar 2007.

[6] M. Barcaro, N. Bianchi, "Interior PM machines using ferrite to substitue rare-earth surface PM machines," International Conference on Elecrical Machines (ICEM), Marseille, France, Sep 2012.

[7] Henk Polinder, Frank F. A. van der Pijl, Gert-Jan de Vilder, Peter J. Tavner, "Comparison of diret-drive and geared generator concepts for wind turbines", IEEE Trans. on energy conversion, vol. 21, no. 3, pp. 725-733, Sep 2006.

[8] Salman, Salman K. "Windmill modeling consideration and factors influencing the stability of a gridconnected wind power-based embedded generator" IEEE Transactions on Power Systems, vol. 18, no. 2, pp. 793-802, May 2003.

[9] Mandic. G, Nasiri. A, Muljadi. E, Oyague. F, “Active Torque Control for Gearbox Load Reduction in a Variable-Speed Wind Turbine", IEEE Transactions on Industry Applications, vol. 48, no. 6, pp. 2424-2423, 2012.

[10] Conroy, J; Watson, R. “Aggregate modelling of wind farms containing full-converter wind turbine generators with permanent magnet synchronous machines: Transient stability studies" IET Renewable Power Generation, vol. 3, no. 1, pp. 39-52, 2009.

[11] VAkhmatov, "Analysis of dynamic behavior of electric power systems with large amount of wind power," Ph.D. dissertation, Ørsted DTU, Kgs.Lyngby, Denmark, 2003.

[12] Hua Geng, Xu, D., Bin Wu, Geng Yang, "Active Damping for PMSG-Based WECS With DC-Link Current Estimation", IEEE Transactions on Industrial Electronics, vol. 58, no. 5, pp. 1110-1119, 2011.

[13] Akhmatov, Vladislav "Variable-speed wind turbines with doubly-fed induction generators Part IV: Uninterrupted operation features at grid faults with converter control coordination" Wind Engineering, vol.27, no.6, pp.519-529, 2003.

[14] Hua Geng, David Xu1, Bin Wu, Geng Yang," Comparison of oscillation damping capability in three power control strategies for PMSG-based WECS", Wind Energ, vol. 14, pp. 389-406, 2011.

[15] Bhowmik, Shibashis; Spec, René; Enslin, Johan H. R. "Performance optimization for doubly fed wind power generation systems" IEEE Transactions on Industry Applications, vol. 35, no. 4, pp. 949-958, 1999. 
[16] Wang Zhong, Sun Yuanzhang, Li Guojie, Li Xiong, "analysis of current loop parameter in the vector control of DFIG wind turbines" Automation of electric power systems, vol. 32, no. 21, pp.91-96, 2008.

[17] Wang Tianyu, Li Guojie, Zhang Yu, Fang Chen, "Resonant Damping for Wind Turbine Electrically Excited Synchronous Generators", Wind energy GridAdaptive Technologies 2014, Chejudo, Korea, 2014

[18] S. Brownlees, B. Fox, D. Flynn, and T. Litter, "Wind farm induced oscillations" Proc.41st Int.UPEC, vol. 1, pp. 118-122, sep.2006.

[19] Jain, A.K.; Ranganathan, V.T. Modeling and Field Oriented Control of Salient Pole Wound Field Synchronous Machine in Stator Flux Coordinates, IEEE Transactions on Industrial Electronics, vol. 58, no. 3, pp. 960-970, 2011.

[20] F. Blaschke, "The principle of Field Orientation as applied to the Transvecktor closed loop control system for rotating field machines," Seimens Rev, vol. 39, no. 5, pp. 217-220, May 1972.

[21] K. H. Bayer, H. Waldmann, and M. Weibelzahl, "Field oriented closeloop control of a synchronous machine with a new Transvecktor control system," Seimens Rev., vol. 39, no. 5, pp. 220-223, May 1972.

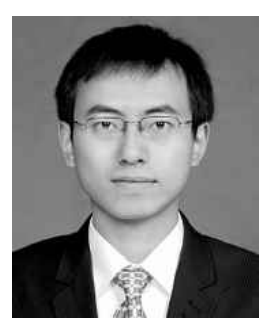

Wang Tianyu He received B.Eng and M.E degrees in electrical engineering from Harbin Institute of Technology University, harbin, China, in 2008 and 2010, respectively. He is currently working toward the Ph.D degree at Shanghai Jiao Tong University, Shanghai.

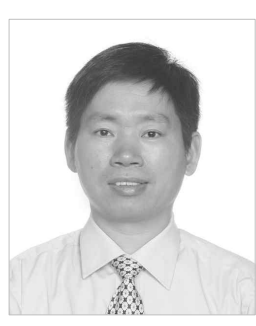

Li Guojie He received Ph.D. degree from Nanyang Technological University, Singapore, in 1999, and got B.Eng and M.E degrees from Tsinghua University, Beijing, China, in 1989 and 1993, respectively. His research interests are power system control, renewable energy, VSC-HVDC, and Micro-grid.

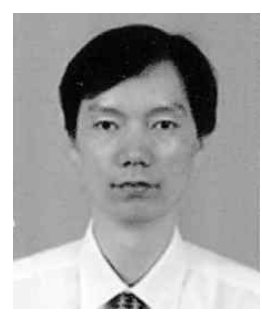

Zhang Yu He graduated from Shanghai Jiao Tong University with the Bachelor Degree of High Voltage Technology. $\mathrm{He}$ worked for East China Electric Testing and Research Institution from 1992. He joined Shanghai Municipal Electric Power Company in 2004. He is now the Deputy Director of Power
Grid Technology Center of State Grid Shanghai Electric Power Research Institute. Mr. Zhang has rich experience in the field of smart grid.

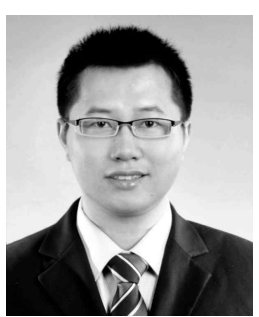

Fang Chen He received Ph.D degree from Tsinghua University, China, in 2011. Now he works in Electric Power Research Institute of State Grid Shanghai Municipal Electric Power Company. His research interests are smart grid, distributed energy and microgrid optimal operation.

\section{Appendix}

Small signal equation parameters:

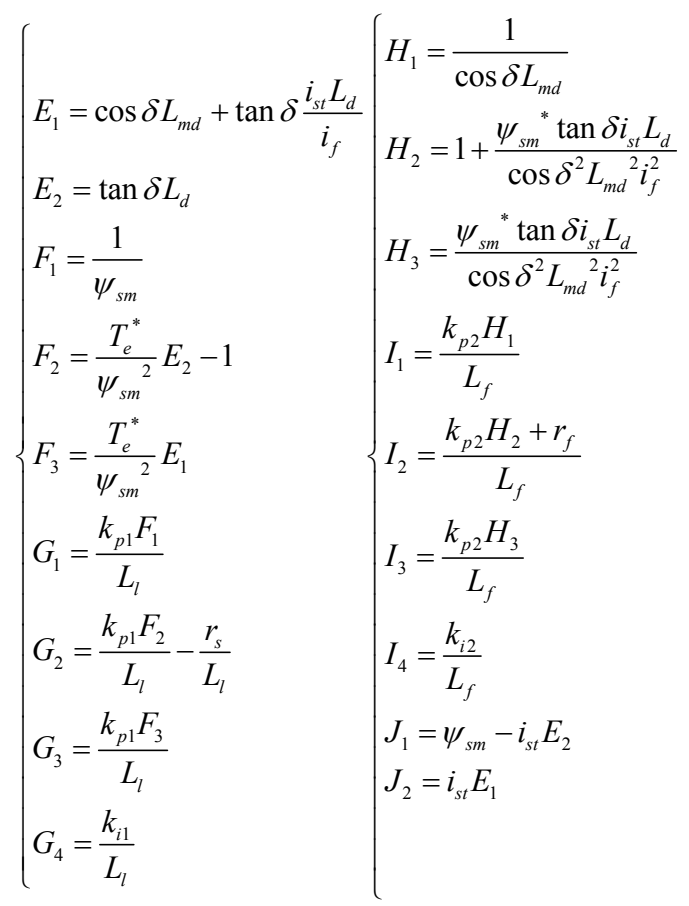

Wind turbine mechanical parameters

$$
\left\{\begin{array}{l}
J_{h}=6.25 \times 10^{6}\left(\mathrm{~kg}^{2} \mathrm{~m}\right) \\
J_{g}=6.511 \times 10^{5}\left(\mathrm{~kg}^{2} \mathrm{~m}\right) \\
K=8.6727 \times 10^{7}(\mathrm{Nm} / \mathrm{rad})
\end{array}\right.
$$

